\title{
Hepsin shows inhibitory effects through apoptotic pathway on ovarian cancer cell lines
}

\author{
KEIICHIRO NAKAMURA ${ }^{1}$, YASUTOMO NASU ${ }^{2}$, ATSUSHI HONGO ${ }^{1}$, TAMAKI MATSUO ${ }^{1}$, JUNICHI KODAMA ${ }^{1}$, \\ SHIN EBARA ${ }^{2}$, ATSUSHI NAGAI ${ }^{2}$, FERNANDO ABRZUA ${ }^{2}$, HIROMI KUMON ${ }^{2}$ and YUJI HIRAMATSU ${ }^{1}$ \\ Departments of ${ }^{1}$ Obstetrics and Gynecology, ${ }^{2}$ Urology, Okayama University Graduate \\ School of Medicine, Dentistry and Pharmaceutical Sciences, Okayama, Japan
}

Received September 12, 2005; Accepted October 31, 2005

\begin{abstract}
In light of the poor prognosis for ovarian cancer patients, the research continues for innovative and efficacious treatment modalities. Along with surgical and chemotherapeutic regimens, gene therapy has emerged as one of the leading contenders in the treatment armamentarium. Hepsin is a type II transmembrane serine protease originally identified in the human liver as a cDNA clone. However, the biological function of Hepsin expression remains unclear. Apoptotic cell was increasingly common among higher proportions of Hepsin transfectants. We discovered that first-time stable transfectants of Hepsin significantly inhibited cell growth in the monolayer, anchorage-independent cell growth in the soft agar in vitro, and tumorigenicity in vivo in ovarian cancer cell lines. These results demonstrated that Hepsin has a potential therapeutic effect that inhibits through up-regulation of p53-dependent apoptosis and caspase- $3,-6$, and -7 activations. Our findings in this study identify Hepsin as a target for new approaches in ovarian cancer treatment.
\end{abstract}

\section{Introduction}

Despite its pervasive impact, the etiology of ovarian cancer and the factors that promote its progression are not yet well understood. Although chemotherapy remains a major treatment modality for human ovarian cancer, chemoresistance is a clinical problem that severely limits the success of the

Correspondence to: Dr Keiichiro Nakamura, Department of Obstetrics and Gynecology, Okayama University Graduate School of Medicine, Dentistry and Pharmaceutical Sciences, 2-5-1 Shikata-cho, Okayama 700-8558, Japan

E-mail: k-nakamu@cc.okayama-u.ac.jp

Abbreviations: p53AIP, p53 apoptosis-inducing protein 1; wt, wild-type

Key words: Hepsin, ovarian cancer, p53-dependent apoptotic pathway, caspase treatment. It is now widely accepted that the apoptotic capacity of ovarian cancer cells is pivotal in determining their responses to chemotherapeutic agents.

Hepsin is a type II transmembrane serine protease originally identified in the human liver as a cDNA clone $(1,2)$. A $1.85-\mathrm{kb}$ Hepsin mRNA is highly expressed in normal liver and kidney tissues and is poorly expressed in other tissues, including the normal prostate and lung. In normal ovarian tissue, Hepsin mRNA is not expressed, and Hepsin overexpression has been reported in ovarian, renal, and prostate carcinomas (3-5). However, the biological functions of Hepsin remain unknown.

The targets of p53-regulated genes or p53-interacting proteins have provided critical information to the understanding of the biochemical and biological functions of the p53 tumor suppressor gene. The purpose of this study is to examine the role of Hepsin in the wild-type (wt) p53-dependent apoptosis pathway and caspase family. We studied the p53 apoptoticmediated factors and performed cell growth in the monolayer, anchorage-independent cell growth in the soft agar in vitro, and tumorigenicity in vivo. We provided new insights into the biological functions and gene therapeutic target in ovarian cancer.

\section{Materials and methods}

Cell culture and media. BG-1, OVCAR-3, CaOV-3 cell lines were derived from human epithelial ovarian carcinoma. These ovarian cancer cell lines were maintained in Dulbecco's modified Eagle's medium (DMEM) with $10 \%$ fetal bovine serum (FBS). The LNCaP cell line was derived from human prostate carcinoma. The prostate cancer cell lines were maintained in RPMI-1640 (Life Technologies, Inc., Rockville, MD) with $10 \% \mathrm{FBS}$. Cells were maintained at $37^{\circ} \mathrm{C}$ in an atmosphere with $5 \% \mathrm{CO}_{2}$ in the air.

Reverse transcription-PCR analyses. In reverse transcriptionPCR (RT-PCR), we used primers 5'-TGTCCCGATGGCGA GTGTTT-3' (Hepsin-F) and 5'-CCTGTTGGCCATAGTACT GC-3' (Hepsin-R), as described (3). The number of PCR cycles resulting in PCR products in the linear logarithmic phase of amplification curve was determined. PCR samples were electrophoresed on $2 \%$ agar gel and visualized by ethidium bromide. 
A

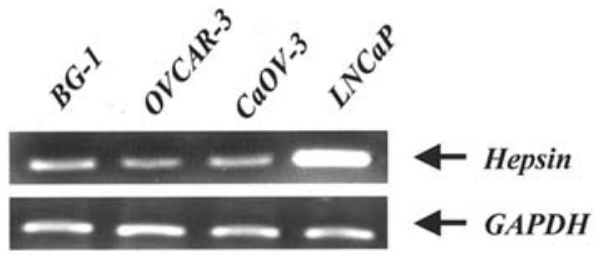

B

1. $\quad 2 . \quad 3 . \quad 4$.

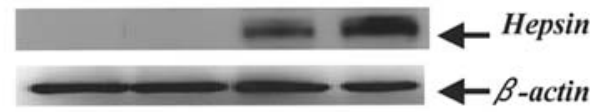

1. Empty vector

C

2. Hepsin 24 h transfected

3. Hepsin 48 h transfected
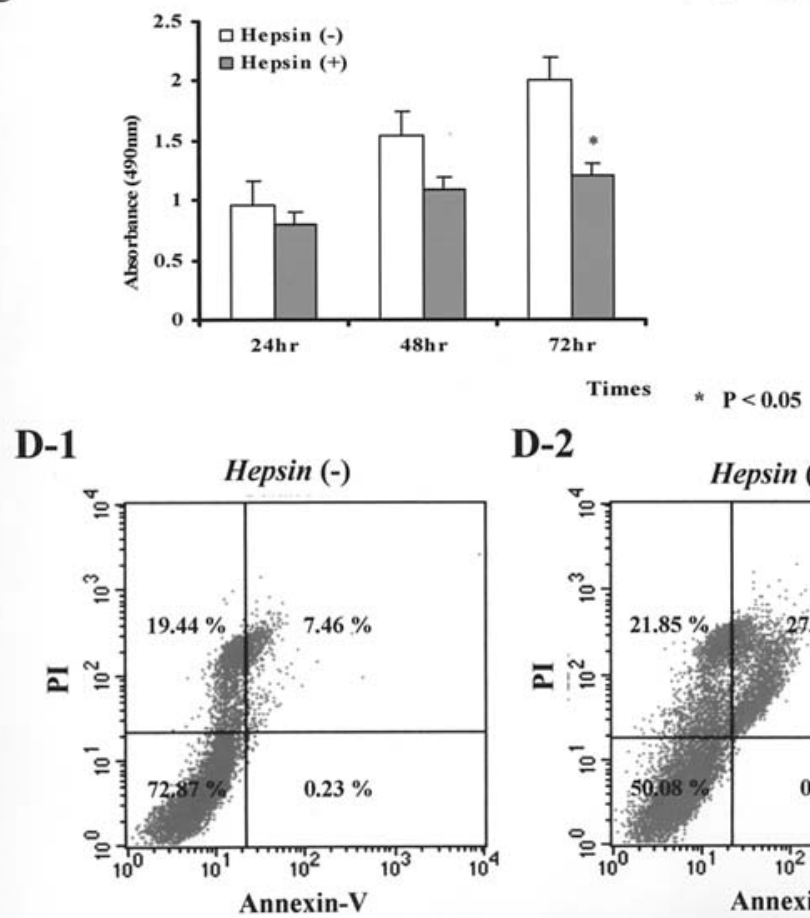

D-2

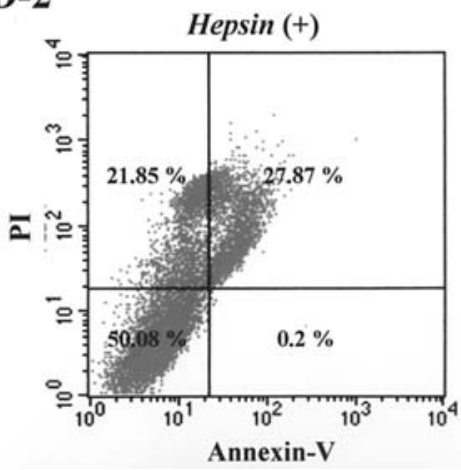

Figure 1. (A) BG-1, OVCAR-3 and CaOV-3 ovarian cancer cells and LNCaP prostate cancer cells were analyzed for Hepsin by RT-PCR. (B) Total cell lysates of Hepsin transient transfected were treated for 0, 24, 48 and 72 h. BG-1 cells were analyzed for Hepsin protein using Western blotting. As a loading control, a $\beta$-actin antibody was used in the same blot. (C) Cell proliferation of MTS assay was analyzed either with or without Hepsin transient transfection for 24, 48 and $72 \mathrm{~h}$ using BG-1 cell lines. The absorbance was read at a wavelength of $490 \mathrm{~nm}$ using an ELISA plate-reader. The assays were carried out through quadruplate transfection experiments. (D) Representative flow cytometric data for apoptosis in the BG-1 cell line either with or without Hepsin transient transfection after $72 \mathrm{~h}$ of treatment [D-1, Hepsin(-); D-2, Hepsin(+)].

Western blot analysis. Cell lysates were collected and estimated using a Protein Assay system (Bio-Rad, Hercules, CA) according to the manufacturer's protocol. The protein from each cell line was subjected to SDS-PAGE and was transferred onto the nitrocellulose membrane. The polyclonal and monoclonal antibodies and working dilution ratios used for immunoblotting were as follows: Hepsin (Cayman Chemical, Ann Arbor, MI), p53, Puma- $\alpha$, Puma- $\beta / \delta$, Noxa, Bcl-2, Bax, Bak, p53AIP1, p53R2, caspase-3, -6, and -7 (Santa Cruz Biotechnology, Santa Cruz, CA), and B-actin (Sigma Chemical Co., St. Louis, MO). The membranes were then incubated with each second antibody. The expressions of antigen-antibody complexes were detected using an enhanced chemiluminesence kit (Amersham Biosciences, Piscataway, NJ).

Generation of transient transfectant. A full-length Hepsin cDNA construct encoring the Hepsin protein was transiently transfected in the BG-1 cell lines using a TransFast transfection reagent (Promega, Madison, WI). BG-1 cell lines were treated either with or without Hepsin for 24, 48 or $72 \mathrm{~h}$.

Cell proliferation assay and FITC-conjugated Annexin V. In order to evaluate the growth effects of Hepsin, MTS assay (Promega) was performed. Cells were seeded into 96-well plates to obtain a density of $5 \times 10^{4}$ cells/well and transfected for 24,48 or $72 \mathrm{~h}$. The absorbance was read at a wavelength of $490 \mathrm{~nm}$ using an ELISA plate-reader (Bio-Rad Systems). Moreover, apoptosis was measured by staining with FITCconjugated Annexin V using a Mebcyto apoptosis kit (MBL, Nagoya, Japan) according to the manufacturer's recommendations with flow cytometric analysis.

Generation of stable transfectant. Hepsin stable transfectant in the BG-1 cell lines was generated using a TransFast transfection reagent. Zeocin $(0.8 \mathrm{mg} / \mathrm{ml})$ (Invitrogen, Carlsbad, CA)-resistant colonies were selected after 4 weeks. Drug 
A

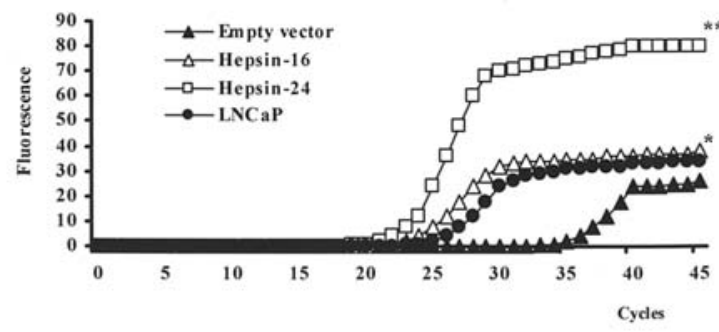

B

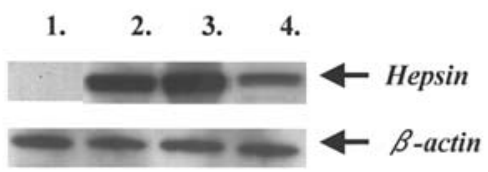

${ }^{*} \mathbf{P}<0.05$

** $\mathbf{P}<0.01$

1. Empty Vector

2. Hepsin-16

3. Hepsin-24

Figure 2. Hepsin was stabley transfected in the BG-1 cell line using a TransFast transfection reagent. Zeocin $(0.8 \mathrm{mg} / \mathrm{ml})$-resistant colonies were selected after 4 weeks. Cells derived from the individual colonies after transfection and drug selections were obtained by cloning cylinders and were then further expanded. (A) Stable BG-1 cell transfectants of Hepsin cells (BG-1/Hepsin-16, 24), an empty vector type of BG-1 ovarian cancer cells, and LNCaP were analyzed for Hepsin by real-time quantitative PCR. As a loading control, a GAPDH was used. (B) Total cell lysates were prepared from stable transfectants of Hepsin cells, an empty vector type of BG-1, and LNCaP were analyzed. As a loading control, a B-actin antibody was used in the same blot.

selections of individual colonies were performed and then further expanded.

Real-time PCR. Real-time quantitative RT-PCR was performed using a LightCycler rapid thermal cycler instrument (Roche Diagnostics, LightCycler, Mannheim, Germany) under the conditions recommended by the manufacturer. The real-time PCR used the primers: 5'-CCAAGGACACCCTCC CTC-3' (Hepsin-F), 5'-AAGAGCATCCCATCATCAGG-3' (Hepsin-R); 5'-TTCCTAGCACTGCCCAACA-3' (p53-F), 5'GACTGGAAACTTTCCACTTG-3' (p53-R); 5'-CAACTAC ATGGTTTACATGTTC-3' (GAPDH-F), and 5'-GCCAGTG GACTCCACGAC-3' (GAPDH-R), as described $(6,7)$. The products were checked by melting point analysis and electrophoretic mobility. Standard curves for the calculation of the number of transcripts were elaborated using plasmids containing the respective amplified fragment as an insert, and were adjusted to use GAPDH as the reference gene.

Cell growth in monolayer. Cells were plated at a density of $2.5 \times 10^{4}$ cells/well in 6-well plates in DMEM with $10 \%$ FBS. Cell proliferations were followed by counting the cell numbers after 1,3, 5, and 7 days. All points were results of triplicate experiments by a hemocytometer, and the mean values were analyzed.

Cell growth in soft agar. A cell suspension ( $1 \times 10^{4}$ cells/well) in $1 \mathrm{ml}$ of $0.2 \%$ Noble agar with DMEM with $10 \%$ FBS was overlaid into a $35-\mathrm{mm}$ dish containing a $0.5 \%$ agar base. Colonies $>0.2 \mathrm{~mm}$ in diameter were counted on day 21 .

Tumorigenesis in nude mice. Cells $\left(2.5 \times 10^{7}\right)$ suspended in $200 \mu 1$ of sterile PBS were injected subcutaneously above the hind leg of 5-week-old male BALB/c nude mice (Charles River Japan, Yokohama, Japan). The established tumor volume was measured weekly as a spheroid from three-dimensional diameters.

Immunohistochemistry. Formalin-fixed paraffin-embedded sections, $4-\mu \mathrm{m}$ thick, were deparaffinized with xylene and rehydrated in ethanol. Endogenous peroxidase activity was blocked by methanol containing $0.3 \%$ hydrogen peroxidase for $15 \mathrm{~min}$. The sections were then treated at room temperature with a primary antibody for $\mathrm{p} 53$, Puma- $\alpha$, Puma- $\beta / \delta$, Noxa, Bax, Bak, p53AIP1, and p53R2, followed by staining using a streptavidin-biotin-peroxidase kit (Nichirei, Tokyo, Japan). The sections were counterstained with hematoxylin.

\section{Results}

The transient transfection of Hepsin increased the progress of apoptosis. The mRNA of Hepsin was determined using quantitative RT-PCR (3). Among the established ovarian cancer lines, Hepsin expression was detected in the $\mathrm{CaOV}-3$, OVCAR-3, and BG-1 cell lines. As a positive control, we used the LNCaP prostate cancer cell line (Fig. 1A). Among these three, the BG-1 cell line exhibited the strongest transformation on anchorage-independent cell growth. For this reason, the BG-1 transfectant was chosen for further experiments. Several previous reports also showed that Hepsin acts during apoptosis and in the $\mathrm{G}_{2}$ phase of the cell cycle in prostate cancer (8). We used both MTS and FITC-conjugated Annexin V assays that examined apoptosis expression transient transfection of Hepsin treatment in the BG-1 ovarian cancer cell line. Protein expression of Hepsin transient transfectant was detected using Western blotting. Hepsin expression was significantly detected only after 72-h treatment (Fig. 1B). Proliferation was significantly suppressed in 72-h transfectant in accordance with the pattern of protein expression $(\mathrm{p}<0.05)$ (Fig. 1C). Representative flow cytometric data revealed that transient transfection of Hepsin for $72 \mathrm{~h}$ showed increased FITC-positive and propidium iodide (PI)-positive signals (Fig. 1D). Therefore, Hepsin was likely to regulate the apoptosis induced by transient transfection of Hepsin.

Evaluation of Hepsin expression stabley transfected BG-1/ Hepsin cells. mRNA from stabley transfected cells was measured by real-time quantitative RT-PCR and was adjusted to the GAPDH levels. As a positive control, we used the LNCaP prostate cancer cell line. Both the mRNA and protein levels of Hepsin were similarly and highly expressed by BG-1/ Hepsin-24 and BG-1/Hepsin-16 cells. However, the empty vector type weakly expressed the mRNA levels of Hepsin. Furthermore, BG-1/Hepsin-24 cells were significantly overexpressed compared to BG-1/Hepsin-16 cells (Fig. 2).

Inhibition of cell growth in monolayer culture. The effect of Hepsin expression on cell proliferation was analyzed in BG-1/ Hepsin-16 and BG-1/Hepsin-24. We found a significant inhibitory effect of Hepsin expression on cell growth in the monolayer cultures of BG-1/Hepsin-16 and BG-1/Hepsin-24 $(\sim 70 \%$ inhibition $)(\mathrm{p}<0.05)$ compared to the empty vector type of BG-1 (Fig. 3). 


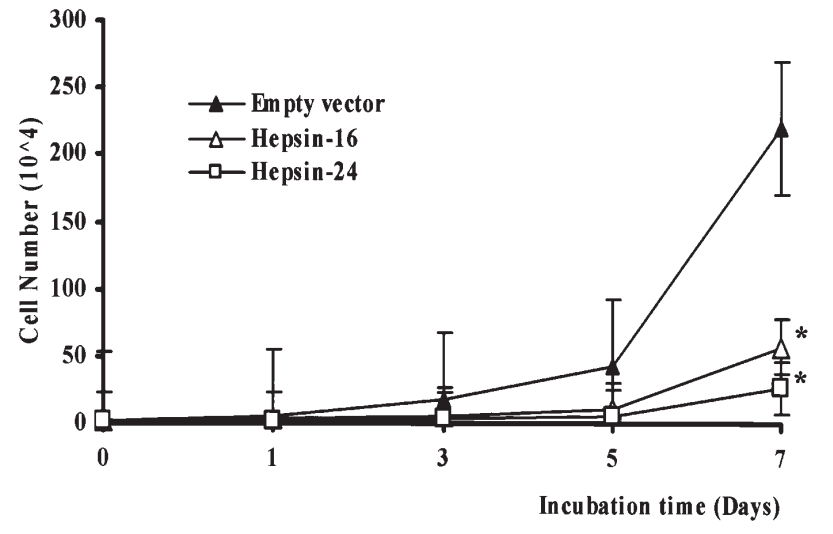

* $\mathbf{P}<0.05$

Figure 3. Monolayer growth of Hepsin stable transfectant cells (BG-1/ Hepsin-16, 24) and an empty vector type in the BG-1 ovarian cancer cell line. Cells were plated at a density of $2.5 \times 10^{4}$ cells/well in 6-well plates and were incubated for 7 days in DMEM supplemented with 10\% FBS. The number of cells was determined after an additional 1,3,5 and 7 days.

Table I. Colony formation on soft agar of Hepsin stable transfectant cells and the empty vector type on BG-1 ovarian cancer cell lines.

\begin{tabular}{lcc}
\hline Cell line & $\begin{array}{c}\text { Average no. of } \\
\text { colonies/dish }\end{array}$ & $\begin{array}{c}\text { Inhibitory } \\
\text { effect }(\%)\end{array}$ \\
\hline Empty vector & 125.3 & 0 \\
Hepsin-16 & 25.6 & $79.6^{\mathrm{b}}$ \\
Hepsin-24 & 8.3 & $93.4^{\mathrm{c}}$ \\
\hline
\end{tabular}

${ }^{a}$ The number represents through triplicate experiments. ${ }^{b} \mathrm{p}<0.05$, ${ }^{\mathrm{c}} \mathrm{p}<0.01$.

Increased accumulation of p53-dependent apoptosis and caspases in stabley transfected BG-1/Hepsin cells. To determine whether the p53 tumor suppressor gene regulates Hepsin expression in ovarian cancer cells, p53 mRNA and protein expression were analyzed in BG-1/Hepsin-16 and BG-1/Hepsin-24 cells. The mRNA and protein levels of BG-1/ Hepsin-24 and BG-1/Hepsin-16 cell showed overexpression of $\mathrm{p} 53$ compared with the BG-1 empty vector. BG-1/Hepsin-24 cells showed the highest overexpression levels compared with BG-1/Hepsin-16 cells (Fig. 4A and B).

Accordingly, we experimented on the promoters of apoptotic cell death, which are pro-apoptotic Bcl-2 protein (Bax-, Bak- and BH-3-only proteins such as Noxa, Puma- $\alpha$, Puma- $/ / \delta$ ), and $\mathrm{p} 53$-regulated apoptosis-inducing proteins (p53AIP1), the repair of damaged DNA proteins (p53R2), and anti-apoptotic Bcl-2 protein (Bcl-2). In BG-1/Hepsin-24, Noxa, Puma- $\alpha$, Puma- $\beta / \delta$, Bax, Bak, p53AIP1, and p53R2 proteins were up-regulated. Subsequently, down-regulation of Bcl-2 resulted in p53-dependent apoptosis. The p53-related apoptosis factors were highly up-regulated in BG-1/Hepsin-24, unlike BG-1/Hepsin-16 and the empty vector type (Fig. 4B).

To investigate the specific apoptotic regulated by Hepsin, we examined the effect of Hepsin on the caspase family by Western blotting. The protein levels of BG-1/Hepsin-24 and
A

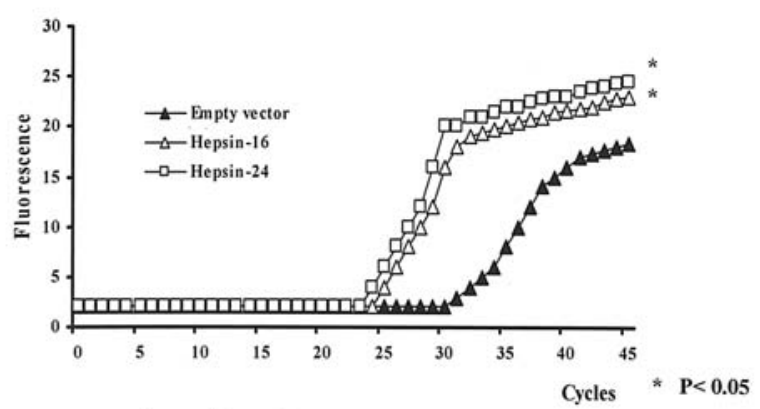

B

1. $2 . \quad 3$.

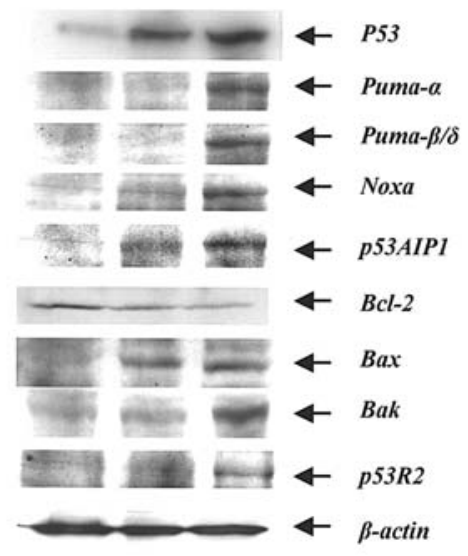

C 1. $2 . \quad 3$.

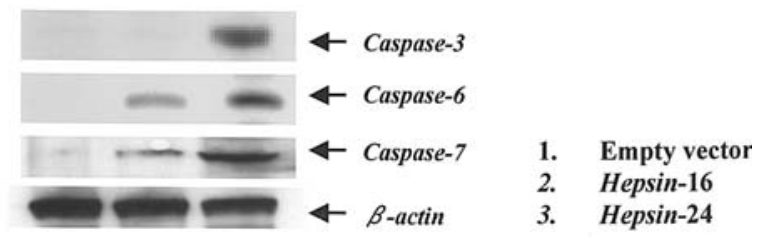

Figure 4. Effect of stable transfection of Hepsin on the expression of the p53-dependent apoptosis protein. (A) Stable BG-1 cell transfectants of Hepsin cells (BG-1/Hepsin-16, 24) and an empty vector type of BG-1 ovarian cancer cells were analyzed for p53 by real-time quantitative PCR, as described. As a loading control, a GAPDH was used. (B) Total cell lysates were prepared from BG-1 Hepsin stable transfectants (BG-1/Hepsin-16, 24) and the empty vector type was analyzed for $\mathrm{p} 53$, Puma- $\alpha$, Puma- $\beta / \delta$, Noxa, p53AIP1, Bcl-2, Bax, Bak and p53R2 proteins using Western blotting. As a loading control, $\beta$-actin antibody was used in the same blot. (C) BG-1/ Hepsin-16, -24 and the empty vector type were analyzed for caspase-3, -6, and -7 proteins using Western blotting. As a loading control, B-actin antibody was used in the same blot.

BG-1/Hepsin-16 showed significant overexpression of caspase3, -6, and -7 (Fig. 4C), but not caspase-1, -2, -8 and -9 (data not shown), compared with the BG-1 empty vector. Moreover, caspase-3, -6 , and -7 of BG-1/Hepsin-24 cells showed the highest overexpression levels compared with BG-1/Hepsin-16 cells.

Inhibition of cell growth in soft agar. The inhibitory effect in colony formation was approximately $80 \%$ higher than the empty vector type. Furthermore, BG-1/Hepsin-24 cells produced a smaller number of colonies compared to BG-1/ Hepsin-16 cells and the empty vector type $(\mathrm{p}<0.05$ or $\mathrm{p}<0.01)$ (Table I).

Inhibition of tumor growth in vivo. We examined the tumorigenicity of BG-1/Hepsin-24 or the empty vector type in nude 
mice. Characteristically, there was a noticeable suppression of tumor growth in a statistically significant manner by BG-1/ Hepsin-24. The extent of reduction in the tumor volume

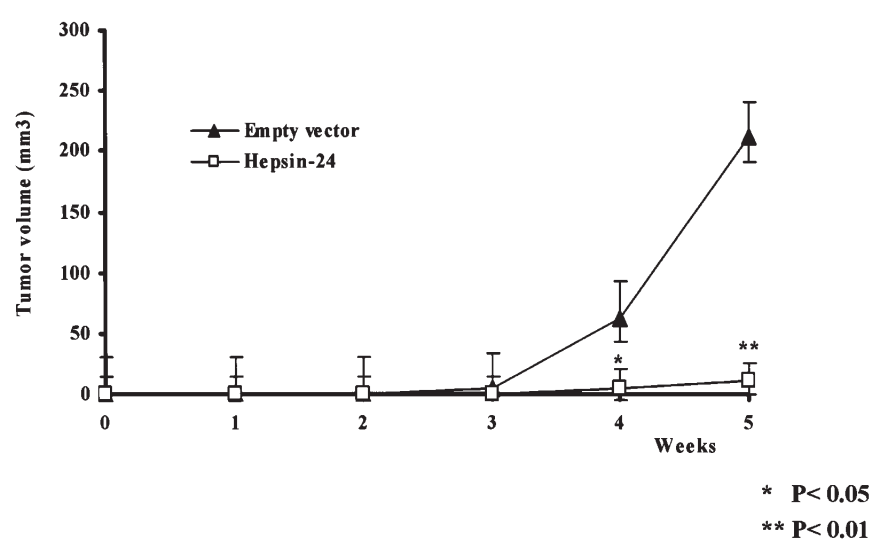

Figure 5. Tumorigenesis of Hepsin stable transfectant cells (BG-1/Hepsin-24) and the empty vector type of the BG-1 ovarian cancer cell line. After $24 \mathrm{~h}$ of serum starvation, each clone $\left(2.5 \times 10^{7}\right.$ cells $)$ was resuspended in $200 \mu 1$ of sterile PBS and injected s.c. above the hind leg of 5-week-old male BALB/c nude mice. The established tumor volume was measured weekly as a spheroid from three-dimensional diameters. Each point represents the mean and SD from 5 mice. The mean tumor \pm SD are shown at the times that tumor measurements were made $(n=5)$. compared to the empty vector type was more than $95 \%$ $(\mathrm{p}<0.01)$ (Fig. 5).

In vivo expression of p53-dependent apoptosis protein. To confirm the p53-dependent apoptosis protein overexpression by immunohistochemistry staining, we used an empty vector and Hepsin transfectants (BG-1/Hepsin-24). The representative staining of the p53-dependent apoptosis factors (Bax, Bak, Puma- $\alpha$, Puma- $\beta / \delta$, Noxa, p53AIP1, and p53R2) were also densely stained in BG-1/Hepsin-24 tissue. Furthermore, p53AIP1 was more densely stained than the other p53dependent apoptosis factors (Fig. 6).

\section{Discussion}

In light of the poor prognosis for ovarian cancer, the research continues for innovative and efficacious treatment modalities. Along with surgical and chemotherapeutic regimens, gene therapy has emerged as one of the leading contenders in the treatment armamentarium.

Data from the present study show that Hepsin is essential for the functional activity of ovarian cancer. Previous reports have documented overexpression of Hepsin in ovarian cancer; however, its biological functions remain to be understood. In the current study, we demonstrated that the overexpression of Hepsin inhibited cell proliferation, colony formation in vitro,
Hepsin

$(-)$

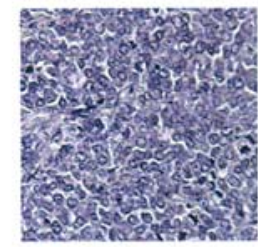

$(+)$

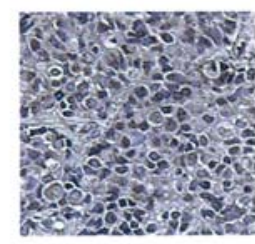

Hepsin

$(-)$

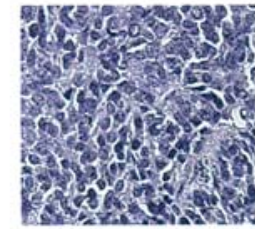

$(+)$ p53

Noxa

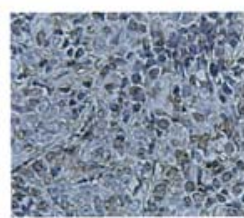

p53AIP1 Puma-a
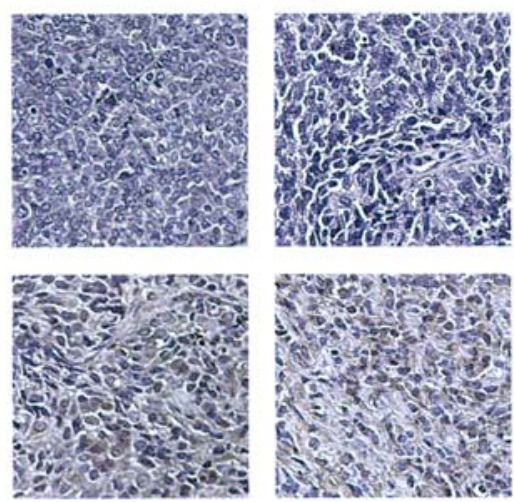

Bax
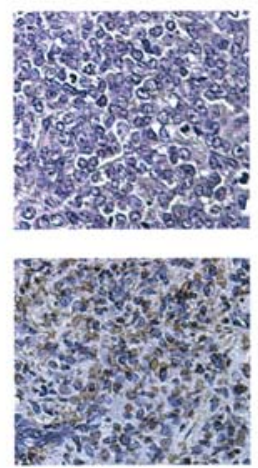

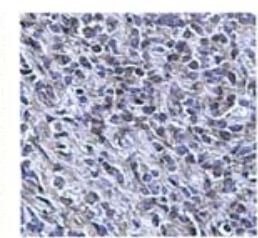

Bak
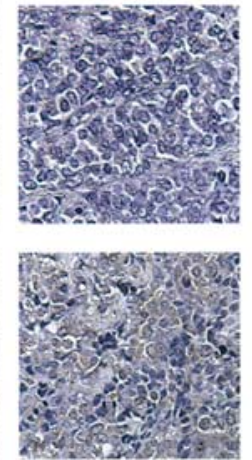

Puma- $\beta / \delta$

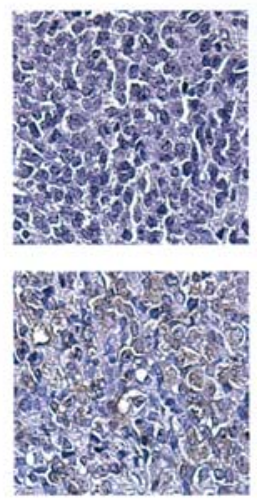

p53R2
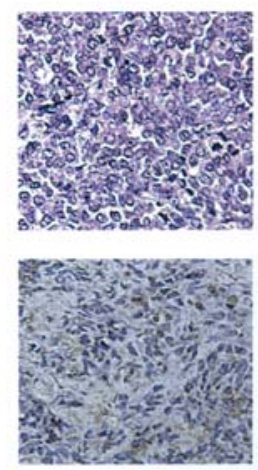

Figure 6. Immunohistochemical analysis of the p53-dependent apoptosis protein transfectants of Hepsin cells (BG-1/Hepsin-24) and the empty vector type in the BG-1 ovarian cancer cell line. After 5 weeks, each tumor was removed, fixed or embedded in paraffin, and 4- $\mu \mathrm{m}$ sections were performed using the

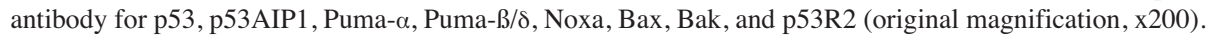


and tumorigenicity in vivo. Prostate cancer studies showed that Hepsin acts during apoptosis and in the $G_{2}$ phase of the cell cycle (8).

DNA damage and oncogene expression lead to the stabilization and activation of the p53 tumor suppressor protein. The wild-type p53 (wt p53) protein exerts inhibitory effects toward the growth of abnormal cells, and has been considered as a guardian of the genome by preventing cancer development (9). To our knowledge, the present study is the first report of Hepsin-induced activation of the p53-dependent pathway. Further research is needed to define the mechanism involved in the upstream activation of $\mathrm{p} 53$ by Hepsin.

Depending on the cellular context, p53 activation can cause cell cycle arrest or apoptosis, and both responses contribute to tumor suppression (10). In this study, we discovered that Hepsin induced activation of p53 leading to a p53-dependent apoptosis.

Several promoters of apoptotic cell death, such as promoters of pro-apoptotic Bcl-2 protein: Puma $(11,12)$, Noxa $(13,14)$, Bax (15), Bak (16), and other promoters such as p53AIP1 (17), and p53R2 (18), were considered to regulate p53dependent apoptosis. In this study, we used protein analysis to study the p53-dependent apoptosis pathway. Our results showed that Hepsin-induced expression up-regulated the Puma, Noxa, Bax, Bak, p53AIP1, and p53R2 proteins. This confirms the fact that Bcl-2, which is a death antagonist and has the capacity to suppress caspase-dependent pathways of apoptosis, plays a potentially important role in p53-dependent apoptosis $(13,19-22)$.

To date, there is no evidence for a regulatory role for Hepsin in apoptotic-mediated caspase signaling complex activity. Our data indicates that p53-dependent apoptosis, which mediated the activation of caspase- $3,-6$, and -7 , was enhanced by Hepsin expression.

In the present study, we discovered that the inhibitory effect of Hepsin overexpression isn't only present in experimental cell growth in the monolayer but also in anchorageindependent cell growth in vitro. In the present study, we first reported the vigorous inhibitory effect of tumorigenesis expression in vivo. In vivo studies showed that the extent of reduction in the tumor volume compared to the empty vector type was more than $95 \%$ (Fig. 5). Combining these results, it is suggested that Hepsin has a potentially therapeutic effect through growth inhibition of the ovarian cancer cell line.

In conclusion, we propose that Hepsin induces activation of apoptosis and inhibits cell growth in vitro as well as tumorigenicity in vivo. Our findings identify Hepsin as a potential therapeutic target gene for new approaches to treating ovarian cancer.

\section{Acknowledgments}

We are grateful to the Center for Prostate Disease Research (Johng S. Rhim) for providing us with a full-length Hepsin cDNA construct encoring Hepsin fusion protein.

\section{References}

1. Leytus SP, Loeb KR, Hagen FS, Kurachi K and Davie EW: A novel trypsin-like serine protease (hepsin) with a putative transmembrane domain expressed by human liver and hepatoma cells. Biochemistry 27: 1067-1074, 1988.

2. Tsuji A, Torres-Rosado A, Arai T, Le Beau MM, Lemons RS, Chou SH and Kurachi K: Hepsin, a cell membrane-associated protease. J Biol Chem 266: 16948-16953, 1991.

3. Tanimoto H, Yan Y, Clarke J, Korourian S, Shigemasa K, Parmley TH, Parham GP and O'Brien TJ: Hepsin, a cell surface serine protease identified in hepatoma cells, is expressed in ovarian cancer. Cancer Res 57: 2884-2887, 1997.

4. Zacharski LR, Ornstein DL, Memoli VA, Rousseau SM and Kisiel W: Expression of the factor VII activating protease, hepsin, in situ in renal cell carcinoma. Thromb Haemost 79: 876-877, 1998.

5. Dhanasekaran SM, Barrette TR, Ghosh D, Shah R, Varambally S, Kurachi K, Pienta KJ, Rubin MA and Chinnaiyan AM: Delineation of prognostic biomarkers in prostate cancer. Nature 412: 822-826, 2001.

6. Ernst T, Hergenhahn M, Kenzelmann M, et al: Decrease and gain of gene expression are equally discriminatory markers for prostate carcinoma. Am J Pathol 160: 2169-2180, 2002.

7. Wilhelm J, Hahn M and Pingoud A: Influence of DNA target melting behavior on real-time PCR quantification. Clin Chem 46: $1738-1743,2000$.

8. Srikantan V, Valladares M, Rhim JS, Moul JW and Srivastava S: Hepsin inhibits cell growth/invasion in prostate cancer cells. Cancer Res 62: 6812-6816, 2002.

9. Gottlieb TM and Oren M: p53 in growth control and neoplasia. Biochim Biophys Acta 1287: 77-102, 1996.

10. Rich T, Allen RL and Wyllie AH: Defying death after DNA damage. Nature 407: 777-783, 2000.

11. Nakano K and Vousden KH: PUMA, a novel proapoptotic gene, is induced by p53. Mol Cell 7: 683-694, 2001.

12. Yu J, Zhang L, Hwang PM, Kinzler KW and Vogelstein B: PUMA induces the rapid apoptosis of colorectal cancer cells. Mol Cell 7: 673-682, 2001.

13. Oda E, Ohki R, Murasawa H, Nemoto J, Shibue T, Yamashita T, Tokino T, Taniguchi T and Tanaka N: Noxa, a BH3-only member of the bcl-2 family and candidate mediator of p53-induced apoptosis. Science 288: 1053-1058, 2000.

14. Schuler M and Green DR: Mechanisms of p53-dependent apoptosis. Biochem Soc Trans 29: 684-688, 2001.

15. Evans DL and Mansel RE: Molecular evolution and secondary structural conservation in the B-cell lymphoma leukemia 2 (bcl-2) family of proto-oncogene products. J Mol Evol 41: 775-783, 1995.

16. Krajewska M, Moss SF, Krajewski S, Song K, Holt PR and Reed JC: Elevated expression of Bcl-X and reduced Bak in primary colorectal adenocarcinomas. Cancer Res 56: 2422-2427, 1996.

17. Matsuda K, Yoshida K, Taya Y, Nakamura K, Nakamura Y and Arakawa K: p53AIP1 regulates the mitochondrial apoptotic pathway. Cancer Res 62: 2883-2889, 2002.

18. Yamaguchi T, Matsuda K, Sagiya Y, Iwadate M, Fujino MA, Nakamura Y and Arakawa H: p53R2-dependent pathway for DNA synthesis in a p53-regulated cell cycle checkpoint. Cancer Res 61: 8256-8262, 2001

19. Kondo S, Barna BP, Morimura T, Takeuchi J, Yuan J, Akbasak A and Barnett GH: Interleukin-1 beta-converting enzyme mediates cisplatin-induced apoptosis in malignant glioma cells. Cancer Res 55: 6166-6171,1995.

20. Henkels KM and Turchi JJ: Cisplatin-induced apoptosis proceeds by caspase-3-dependent and -independent pathways in cisplatinresistant and -sensitive human ovarian cancer cell lines. Cancer Res 59: 3077-3083, 1999.

21. Wu GS and Ding Z: Caspase 9 is required for p53-dependent apoptosis and chemosensitivity in a human ovarian cancer cell line. Oncogene 21: 1-8, 2002.

22. Troy CM, Stefanis L, Prochiantz A, Greene LA and Shelanski ML: The contrasting roles of ICE family proteases and interleukin1 beta in apoptosis induced by trophic factor withdrawal and by copper/zinc superoxide dismutase down-regulation. Proc Natl Acad Sci USA 93: 5635-5640, 1996. 